\title{
A qualitative study of UWL students with dyslexia and how they cope with the demands of higher education
}

\begin{abstract}
This proposal is focused upon and examines the experiences of students with dyslexia in higher education. Several previous researchers had conducted similar studies into the insights of students with dyslexia, ${ }^{1-3}$ however it was still an insignificant amount. An evaluation was made through the insight and experiences students had of their everyday lives. The participants of this study were all University of West London undergraduate students, and were all professionally assessed as dyslexic. The sample consisted of five participants), three females and two males with a range of different ages and courses. Data was collected using a qualitative approach. This was the most appropriate as it would have been very difficult to describe and examine experiences with numbers by opting for a quantitative approach. Semi structured interviews were conducted and analysed using the Thematic Analysis methodology as described by Braun \& Clarke. ${ }^{4}$ All participants were overall satisfied with the support and provision they had received from their university (UWL); having said this, further investigation and research is needed in order to examine perceptions and attitudes of the lecturers and mentors of UWL and other institutions with regards to dyslexia.
\end{abstract}

Volume 9 Issue 5 - 2018

\author{
Naomi Duncan \\ University of West London, UK
}

Correspondence: Naomi Duncan, University of West London, UK, Email omaduncan@gmail.com

Received: October 18, 2017 | Published: October 10, 2018

\section{Introduction}

\section{What is dyslexia?}

There is a diversity of definitions and many views have been expressed when describing the phenomenon of dyslexia. Riddick ${ }^{5}$ described dyslexia as a hidden disability; that is most common of the Specific Learning Difficulties (SpLD), as there are no obvious external signs for people to recognise in order to diagnose. Dyslexia affects the way information is processed, stored and retrieved (Dyslexia and Specific Learning Difficulties in Adults, n.d.). Common problems occur with memory, speed of processing, time perception, organisation and sequencing (Dyslexia and Specific Learning Difficulties in Adults, n.d.). Dyslexia can be said to encompass problems with language processing and the impact this has on one's ability, in particular writing and reading. ${ }^{6,7}$ Visible signs of weakness in literacy are seen to be a useful way of diagnosing dyslexia, although even this is a common misconception as dyslexia is not only about literacy. By literacy this means the ability to read and write (My Child Is Struggling with Studies. What Should I Do? n.d.). Dyslexia is thought to affect approximately $10 \%$ of the population, with $4 \%$ being severely affected. An estimation of around 375,000 children have dyslexia in the UK alone ${ }^{8-10}$ Rising numbers of students in the UK who have dyslexia are applying for and studying already at university. ${ }^{11}$

However, when trying to describe and define dyslexia, numerous difficulties arise due to the different types of dyslexia and the many aspects to it such as the genetic and environmental components. Dyslexia concerns many disciplines and each of these make a contribution towards it. ${ }^{12}$ The International Dyslexia Association $(2002)^{13}$ defines dyslexia as a specific learning disability that has a neurological origin. Dyslexia is characterised by the difficulties with accurate and/or fluent word recognition and by reduced decoding and spelling abilities. Difficulties as such result from a deficit in the phonological component of language which is often unexpected in relation to various other cognitive abilities and provision of effective classroom instruction. Secondary consequences may include difficulty with reading comprehension that can impede the growth of vocabulary and background knowledge.

Dyslexia is widely recognised to have a genetic component. Riddick ${ }^{5}$ conducted a project on children with dyslexia and their family homes. Fifty percent of the children who participated were found to be brought up in families where one parent was thought to have shared similar problems as a child. It was found that seventeen out of the eighteen cases, a parent was identified as probably dyslexic after their child was assessed and diagnosed with dyslexia. Two mothers were also confirmed as being dyslexic after being formally assessed following their child's identification. This study showed a raised number of families sharing the genetic predisposition of dyslexia; however it was not proven to be solely genetic. Environmental influences and type of upbringing could have played a role within this study, but these elements were unnoticed. This study was also supported by the findings of Grigorenko ${ }^{14}$ who reported that the risk of dyslexia is 8 times higher in children with a parental history of reading difficulties or dyslexia diagnosis. This also makes identical twins more prone to dyslexia if the other twin has been diagnosed or has obvious difficulties compared to non-identical twins. A study by Riddick $(1996)^{5}$ on identical and non-identical twins reported the concordance rate for reading problems in identical twins was $70 \%$ compared to $43 \%$ for non-identical twins.

Having said this with much evidence to support the genetic theory, researchers claim that not everybody with genes for dyslexia will be affected by it. If this was the case, both studies above would have a $100 \%$ concordance rate. This means that the environment plays a significant role in a person's development as well as genetic 
components. Our brains are not completely formed at birth and develop and are shaped by our everyday environments. ${ }^{15}$ With a more stimulating and interactive environment, brains will flourish more.

\section{Late diagnosis and impact on self-esteem}

Many unfortunate children and students who have dyslexia but are not yet diagnosed, are often characterised as 'thick', 'lazy' and stupid' as peers around them simply do not understand or have any other explanation for them not exceeding or even achieving the standard grades at school. Several studies have shown that when dyslexia is undiagnosed, a lot of anxiety and frustration can be caused for the individual involved. ${ }^{5,16}$ Depending on the severity of dyslexia, students can experience various levels of difficulties that can affect, in some cases, every aspect of their lives. The lack of support and appropriate help can have long term effects for people with dyslexia leading up to and throughout adulthood. ${ }^{17}$

Farmer, et al. ${ }^{1}$ established that students with dyslexia can suffer with the difficulty of their personal independence as they have to cope with the course workload, a new living environment, deadlines, different ways of learning, making new friends and social circles as well as dealing with their finances independently with parental support or the support of family members. This can be overwhelming to any student regardless, but students with dyslexia are challenged in both their intellectual and social lives. ${ }^{1}$ Furthermore, it is not just the change of the environment that can impact their life, but also the people in their lives plays a significant part too. People with dyslexia often have to endure the negative experiences from teachers, parents, friends and peers who misunderstand them due to the lack of obvious signs making dyslexia difficult to recognise. ${ }^{18}$ This hidden disability eliminates; those who are undiagnosed, the support that is well needed and that one craves for. The people surrounding their life can recognise their potential to succeed but cannot explain the reason for their academic failings, which can be incredibly frustrating for all parties involved. Watkins \& Dong ${ }^{19}$ showed through their research that there is a strong positive correlation between a child's self-esteem and their school achievement. Children with dyslexia fear that due to their academic failure, the support and love of their families will be lost. ${ }^{20}$ Without high self-esteem, self-belief is dropped and it inevitably results in academic failure which some children; as mentioned above, results in the fear of loss of support. A vicious circle that some children may experience due to not being diagnosed. In relation to the interaction between teachers and pupils with dyslexia, Dale \& Taylor $^{21}$ found that adults with dyslexia described how miserable their life was during school because their teachers' lack of support and understanding. People with dyslexia seek 'understanding and recognition'. Further empirical evidence conducted by Morgan \& Klein ${ }^{17}$ confirmed that late diagnosis in adulthood left adults with dyslexia feeling inadequate, angry and frustrated through their previous years of life. The impact of achievement plays an important role in students' lives also. Gibson \& Kendell ${ }^{2}$ gave great insight into students' thoughts on factors impacting their achievement. The students who participated had not been diagnosed as dyslexic until they entered higher education $(18+)$. Due to late diagnosis, this led towards certain feelings of failure within the school system due to the deprivation of support from early on, in turn this supressed their positive feelings towards education as a whole.

\section{The importance of early identification}

It is said that any learning difficulty is known to have a significant impact on education and learning and also on the acquisition of literacy skills. ${ }^{10}$ Long, ${ }^{22} \mathrm{Hall}^{23}$ suggested that dyslexia can have impact upon an individual's learning and social and emotional wellbeing. However, the impact of these important areas can be positive on an individual with dyslexia if the right support and identification is provided. With early identification and support, children and young adults can obtain a shared successful outcome as non-dyslexic children and students. Sherman (2002 cited in Carden, 2007: page 7) declared the importance of early identification and early intervention. "While dyslexia is brain based and lifelong, it is amenable to educational intervention. The educational environment can translate a distinct learning difference into a profound learning disability or it can trigger neural weaknesses and encourage latent strengths to bloom into competencies and talents. With raised awareness and appropriate training, recognising the differences that people with dyslexia have and providing them the help needed is impeccable".

One issue that makes early identification difficult is the belief that a child cannot be diagnosed as dyslexic until about the age of $7 .^{5,24}$ Unanimously, it have been found through a variety of research that after they are assessed, dyslexic students feel relieved and more excited. The label of dyslexia has finally given them the answer to their problems. ${ }^{5}$ Dowana ${ }^{25}$ reported from her study that most of the university students felt better when they knew that dyslexia was the cause of their problems. They felt relieved to know there was an explanation for their academic status and that they wasn't just 'stupid' or 'thick'. This helped them recognise that help is available to them from their schools and universities, especially where there is a large amount of work that they have to deal with for deadlines and exams. Moreover, previous studies into this area of early identification express the importance of this as early identification is vital in the case of dyslexia. Research has shown that later assessment in life found some adults felt resentful for going through life believing they were unintelligent and resented the loss of opportunities for a better education and a brighter future. ${ }^{17}$

An early study by $\mathrm{Cain}^{26}$ aimed to raise the awareness of dyslexia in higher education. The study consisted of testaments to what it is like to be a dyslexic student at university. It also illuminated the problem by emphasising all the different manifestations or warning signs of dyslexia besides the obvious signs of writing, spelling and reading. The students' revelations also echo into general research of into dyslexia. Several main points were made that the disability is often accompanied with one more problems including short attention span, problems with coordination, and problems with organisation, lack of focus, memory problems, word association difficulties and also complications with speech.

Despite there being a large variety in research into dyslexia in the early 1990's to present day, the literature on dyslexia falls mainly within a few categories:

1. The attempts to investigate the nature and explain the causes of dyslexia is lacking.

2. The focus upon actual manifestations of dyslexia and/or its symptoms. This area does not have enough research and this is a highly important aspect of dyslexia.

3. A number of studies; as would be expected, focus on the support issues and how students can be helped to overcome the barriers they may face as well as how teachers or lecturers can help their pupils or students. ${ }^{27,28}$ However, the literature providing 
information about the voices and experiences of students with dyslexia in higher education is still limited. ${ }^{29}$

An increasing number of students are entering higher education are being diagnosed with dyslexia or dyslexic related problems. In 1996, the proportion of dyslexic students not identified as dyslexic until reaching higher education system was over $40 \% .^{9}$ The literature directed specifically with dyslexia at university is inadequate. More research into experiences of students with dyslexia needs to be conducted as well as research into teacher and lecturer experiences for supporting students with dyslexia. A study by Cameron \& Nunkoosing ${ }^{30}$ is one of a few studies that looked into and explored the experiences and perspectives of lecturers on students with dyslexia. This study also looked into the support of the learning difficulty in higher education. They found that those who had personal and meaningful experience with people who have dyslexia showed to have genuine interest in both experience and perspective of dyslexia compared to those who didn't. This study like several others can be shown the help raise the awareness of support for people who have dyslexia and also the importance for early identification. Teachers and lecturers also should be showed how to adapt the classroom or study area for all kinds of students as research has shown that people with dyslexia have different learning styles compared to non-dyslexic people (Mortimore, 2002).

\section{Qualitative approach}

The data for this research was gathered using a qualitative paradigm. The qualitative approach takes the information needed directly from the participants that are involved and listens to the different emphases that each participant gives ${ }^{31}$ Each individual conceives differently to the same or similar situations and the interpretation that each person gives of the world is unique to them. ${ }^{32}$ Each individuals experience is incredibly valuable and significant when giving insight into their world and their situation. From this research, more insight can be gathered into the experiences of students who have dyslexia in higher education.

\section{Semi structured interviews}

It was taken into consideration that people with dyslexia experience difficulties with reading, spelling and writing. ${ }^{33}$ The best instrument for data collection in this case was semi structured interviews. The participants involved wouldn't have to do a great deal of reading, spelling or writing throughout the study in order to ease their experience and make it as relaxing as possible. Semi structured interviews was also selected as it has been found that people with dyslexia found it very frustrating and hard to express their thoughts in writing. ${ }^{3}$ Interviewing is one of the most applied techniques for conducting systematic social inquires such as the experiences and thoughts of a particular group in society. ${ }^{34}$ Body language and behaviour can also be observed at the same time as listening to personal experiences which also gives rich data for analysing. Questions can be clarified and explained, and answers can be expanded with this technique, making it the most suitable way for gathering rich and in depth data that is needed.

\section{Thematic analysis}

Thematic analysis is a very common form of analysis in qualitative research. Themes within the data are extracted and emphasised to later be examined and categorised in order to explain and understand the patterns within the data. ${ }^{4}$ Such themes can then be later backed up and explained with previous research. This method of analysis was most appropriate as it uses the bottom up approach. The bottom up approach is a strategy used for the process of information and the ordering of knowledge. This approach pieces together systems of information in order to identify more complex systems. Through the individual base elements first being specified, these elements of data are then linked together forming larger subsystems that in turn are also linked. Data ends up growing to be complex and whole. ${ }^{35}$ Thematic analysis will be described in more depth throughout the methods section.

\section{Research question and aims}

Over the past few decades, an increase in the interest in trying to find what dyslexia is and where it originates from has arisen. Many researchers have focused upon children and the effects dyslexia has in their lives. When this research proposal was decided, there was limited coverage and insight about students in higher education who have dyslexia. This proposal aims to gather a better and more holistic picture by looking to establish the participant's experiences throughout higher education and before entering higher education. By listening to the students speak about their lives and problems that they face in order to conquer the completion of their courses, as well as their previous experiences and downfalls throughout primary and secondary school, a deeper picture can be drawn for analysis and conclusion. This proposal allowed each participant the opportunity to express their beliefs and thoughts regarding their difficulties throughout education. Insight has been given into how they have coped and what kind of support, if any, has been available to them. Lastly, some of the interview questions were directed into exploring the effects that dyslexia may have had on their social lives and selfesteem.

\section{Research aims/questions:}

1. The aims of this research is to get an inside perspective of students coping with dyslexia in higher education

2. Insight given into their past experiences before higher education

3. Find out how proactive the chosen institution is with the students

\section{Methods}

\section{Design}

This study used a qualitative approach in order to explore the experiences of higher education students with dyslexia and how they cope with the demands of higher education. The method used for this approach was semi structured interviews, this technique produces rich and in depth data as it is unstructured and open ended. A semi structured interview would bedeemed appropriate for gathering data for the qualitative approach because the interview is flexible to allow the research to really get into the participants shoes and understand their experiences fully.

In qualitative research, Thematic Analysis is seen as one of the most commonly used forms of qualitative analysis. Thematic Analysis summarises and explains the data as well as examining and identifying patterns or themes which can then be analysed and further investigated in relation to the phenomenon they are associated with, in this case dyslexia.

TA has many similarities to Grounded Theory and Interpretive 
Phonological Analysis, however, TA is not reliant on theoretical or epistemological approaches (Braun \& Clark, 2006) ${ }^{4}$ and in turn this method of qualitative analysis is more flexible. TA also allows for the perception of patterns and themes then produces an understanding of the information and topic. ${ }^{35}$

The use of semi structured interviews as a form of qualitative data collection allows the researcher to gather more detailed information on the experiences of each participant. This method was most appropriate as research interview seeks to describe the meanings of central themes in the voice of the participants and the main task is to comprehend what the participants say. ${ }^{36}$ In comparison to other qualitative methods such as online data collection, this alternative method would be seen as less appropriate in terms of possible distress and harm to participants being caused through recollection of experiences which may be deemed as a negative ethical implication. However in order to abide by the British Psychological Society's (BPS) ethical guidelines, many ethical considerations were put into place (refer to ethical considerations section of methods).

\section{Participants}

The participants used in this study were a mixture of male and female students with dyslexia; three females and two males. There was a total of five participants $(n=5)$ included in the analysis, all of which had been diagnosed with dyslexia. The demographics recorded were the age of participants', the course they study, their gender and when they were diagnosed with dyslexia (Table 1 in results section). However their ethnic background was not recorded due to this particular demographic not having a prominent impact on experience. The participants were given pseudonyms in order to protect identity. The participants were recruited through an online university network called SONA systems, where the study was advertised. Participants for the study were all UWL undergraduate students with dyslexia; however they were required to be proficient in English to fully take part in the semi structured interview. Participants were then able to get in touch by email and the announcement on the psychology network on blackboard.

Table I Demographics recorded from participants

\begin{tabular}{|c|c|c|c|c|}
\hline Pseudonym & Age & Gender & $\begin{array}{l}\text { Course } \\
\text { studied }\end{array}$ & Diagnosed \\
\hline Janice & 26 & Female & Psychology & $\begin{array}{l}\text { Beginning of Second } \\
\text { Year at University }\end{array}$ \\
\hline Maisy & 28 & Female & Psychology & $\begin{array}{l}\text { Start of University } \\
\text { (Foundation Year) }\end{array}$ \\
\hline Alice & 19 & Female & Hospitality & $\begin{array}{l}\text { Start of University } \\
\text { (Year One) }\end{array}$ \\
\hline Malcom & 21 & Male & Psychology & Year I 3 (Sixth Form) \\
\hline Michael & 21 & Male & Psychology & $\begin{array}{l}\text { Start of University } \\
\text { (Year One) }\end{array}$ \\
\hline
\end{tabular}

\section{Materials}

A semi structured interview was devised for this study (Appendix 1). Each participant was audio recorded and data was later transcribed. A laptop and separate audio recorder (Dictaphone) were both used to record the interviews. Two apparatuses were used in case one failed and a backup record of the data was in place.

\section{Procedure}

Before proceeding to advertising the study, a pilot study was conducted in order to gain knowledge on whether the questions that were to be asked were appropriate and whether the amount of questions being asked was suitable. From the pilot study, it was discovered that more questions were needed, and more prompts were required so each participant could give more in depth information on their experiences. After being satisfied with the questions, the study was then put forward to the SONA systems for advertisement. After receiving the approval required, the study was then live for participants to be recruited through in order to proceed to the interview. Participants were made aware of the study through teachers and advertisements on Black Board which is visible to all, emails directly to the researcher allowed participants to respond to the study on SONA. A participant information sheet was supplied to each participant at the beginning of the interview. This sheet informed participants on relevant details about the study and their ethical rights (Appendix 2). Each participant who took part was also given a consent form to fill out prior to the interview which informed them of their rights and what they were agreeing to by participating in the study (Appendix 3). Each interview took place at any available given room in the University of West London Paragon site at that designated time; the room requirements included a quiet room that would be available for a full hour at a time. Each interview lasted no longer than an hour ranging from 30.5 minutes to 45 minutes. Participants who took part and studied Psychology were each granted 5 participation points. Throughout the interview, the participant was asked a series of questions with several prompts in place. Once the interview finished, each participant was debriefed and they were asked if they had any questions. After each interview was completed and each participant allowed the data to be taken forward, the next process of the study began. Participants were assured in order to protect confidentiality that once the data had been transcribed, the recordings would be deleted. From this, data was later transcribed and analysed using the bottom up inductive method of Thematic Analysis (TA), as described by Braun \& Clark. ${ }^{4}$

Six key steps were specified when analysing data with Thematic Analysis. In order, these steps include data familiarisation, generating initial codes, searching for themes, theme review, theme definition and labelling, and finally producing the report. The first phase for analysis was data familiarisation. Data was read and re-read allowing the identification of patterns and occurrences, this is described as the process of 'seeing'. ${ }^{35}$

This initial step is stressed by Braun and Clarke (2006) ${ }^{4}$ as it is the most important step due to the basis of the analysis being provided. The second phase was the encoding stage, also known as the 'seeing as' stage ${ }^{35}$ This step is a systematic way of categorising and attaining meaningful amounts of data so that patterns can be described. This allowed links to be identified in the data, in which themes began to emerge from. The next phase was theme searching. The combination of codes from the previous phase allowed overarching themes to be recognised. These themes accurately depict the data. Themes were then reviewed to see how they supported the data and the overarching theoretical perspective. This phase allowed themes to be understood and explained accurately. The definition of each theme was the fifth phase. In this stage, aspects of the data were apprehended, and were specifically related back to the entire picture of the data or disregarded. All themes that were extracted by this stage should accurately 
represent the data entirely. By the end of this phase, each theme can be explained in a few sentences. Braun \& Clarke $^{4}$ noted the significance of researchers thinking about names for themes that ideally give the reader a full sense of the theme and its importance. The final phase was producing the report. In this stage, themes that emerged were presented in a table of themes and subthemes. Commonalities and differences were presented, and quotes from the transcriptions were used to elaborate and illustrate the full meaning of how each theme and subtheme were fabricated.

\section{Ethical considerations}

In order to abide by the BPS guidelines, participants were given consent forms to fill out briefing describing the procedures involved in the study. A participation information sheet was also supplied informing them of their ethical rights and what is to be expected as well as useful contacts in case the participant had any questions or needed to discuss the study with anyone. Data was assured to be kept confidential and anonymous by using pseudonyms and any names or organisations mentioned were to be removed so identity was untraceable back to each participant. ${ }^{37}$ Some sensitive subjects may have arisen during the interviews however each participant knew they had the right to withdraw at any stage of the study if they felt at all uncomfortable. This was stressed as well as their data that had been obtained would also be erased.

\section{Analysis and discussion}

The aim of this research proposal was to explore and gain valuable insight into students' with dyslexia lives and how they cope with the demands of higher education, and also to explore what kind of difficulties they were confronted with. All participants involved had very similar thoughts and opinions on their experiences with life as a person who is dyslexic. Some thoughts were more in depth than others but overall, each individual helped create significant insight for analysis using the qualitative method of thematic analysis. It has been identified throughout this research that early identification is crucial for younger people with dyslexia and new adopted ways of managing and supporting those with dyslexia needs to be practised and applied.

Below is the table of demographics that were recorded. These demographics were deemed most appropriate for the analysis and evaluation of participants.

Pseudonyms were given to each participant in order to ensure confidentiality and privacy. Age was recorded as this demographic helped evaluate the differences in experiences of each participant due to the variances in years of experience. Gender was recorded to see if there were any commonalities or differences between them as this would be very interesting to discover.

The course studied was noted due to participation points being awarded, as well as the practicality of each course (whether they were more practical or literacy based in order to determine difficulties with their learning environments).

Finally the age when they were diagnosed was the last piece of information taken as this is a key piece of material dictating the experiences they had and continue to have.

Below is the table of themes and sub-themes that were conceptualised from the transcripts. Some themes are more general while others are more specific. To refer back to all six transcripts of the interviews, please see Appendix 4, 5, 6, $7 \& 8$.

In the above Table 2, the three main themes that emerged from the data are presented, each with several sub themes which are a more in depth extension of the main themes to further describe the data. Each participant had individual insights into coping with dyslexia, however all participants drew attention on similar or the same issues which helped identify and create these themes above. All participants were happy to disclose their past and present experiences with having dyslexia; some more than others as some transcripts are longer, so the information gathered is a healthy amount and many themes derived from each transcript. Below, each theme is explained in depth with references to transcripts and previous research for emphasis and better understanding.

Table 2 Themes and subthemes derived from the participants' experiences with higher education that have dyslexia

\begin{tabular}{ll}
\hline Theme (+ sub -themes) & Example quotation and participant/line number reference (to appendices) \\
\hline I. Emotional Impact of Dyslexia: & I.I 'The anger crept in because I was like how is it possible that they could have missed this'( $\mathrm{PI}$ : line I I 0, II I) \\
I.I Anger/Frustration & I.I 'It's frustrating being compared to Children'( $\mathrm{P4}$ : line 5, 6) \\
I.2 Stupid /Lazy & I.I 'They thought I was being lazy, that was so frustrating' (PI: line I47, I48) \\
I.3 Relief & I.2 'I thought obviously I'm stupid' (PI: line I53)
\end{tabular}

1.2 'Growing up was a negative experience with no support and many teachers calling me lazy and would say 'stop being stupid and just try' like I wasn't trying hard enough' (P3: line I2,3) I.2'people would huff and call me stupid' (P4: line 23)

1.3'It was definitely a relief' (PI: line 108)

I.3'when I found out, relief was the biggest feeling' (P4: line 50)

1.3 'it was a weight off my shoulders, a relief really'(P5:line 43,44)

2. Understanding Learning Styles: $\quad 2.1$ 'I am quite a visual learner I can look at information ex amount of times in order to process' (PI: line I29)

2.I Visual (spatial) $\quad 2.1$ "I learn visually the best so looking at work and making it a way I can visually dissolve it in my brain(P3: line 56)2.2 'with learning I like to listen' (P4: line 56)

2.2 Auditory (listening)

2.2 ' like to listen and interpret things in my own way of understanding. So I record lectures and make my own voice notes'. (P2: line 25, 26, 27) 
Table Continued...

\begin{tabular}{|c|c|}
\hline Theme (+ sub -themes) & Example quotation and participant/line number reference (to appendices) \\
\hline 2.3 Verbal (linguistic) & $\begin{array}{l}2.3 \text { 'I learn a lot verbally so I like speaking too. I like listening to others speak then interpreting it in my own } \\
\text { way so I understand’ (P5: line } 37,38,39)\end{array}$ \\
\hline 3. Self-concept: & $\begin{array}{l}\text { 3.I'I think I found myself... has made me feel better about myself and I don't feel separate to everyone now' } \\
\text { (PI: line I0I, I40, I4I) }\end{array}$ \\
\hline 3.I Self-esteem & 3.I 'no longer am I disappointed in myself or upset' (P4: line 52,53) \\
\hline 3.2 Self-belief & 3.I'I feel more confident however as I feel lifted now' (P2: line 47) \\
\hline \multirow[t]{7}{*}{ 3.3 Strengths/Weaknesses } & 3.2 'I feel more comfortable in myself, I have moreconfidence' (P5: line 52, 53) \\
\hline & 3.2 'I have come to believe in myself more like I can actually do it rather than I can't do' (PI: line I0I, I02) \\
\hline & 3.2 'things are more positive, I feel so much better about myself' (P4: line 67,68$)$ \\
\hline & 3.3 'I believe I can achieve like everyone else’ (P5: line 53) \\
\hline & 3.3 'My weaknesses are definitely the reading... it's so hard to concentrate and understand' (PI:line 94, 96) \\
\hline & 3.3 'my strengths are my enthusiasm and determination' (P4: line 40) \\
\hline & $\begin{array}{l}3.3 \text { 'my weakness is reading, then writing, then my lack of concentration and how easy I can procrastinate' (P5: } \\
\text { line } 32,33 \text { ) }\end{array}$ \\
\hline
\end{tabular}

\section{Emotional impact of dyslexia}

The first theme that emerged was the emotional state of each participant from the impact of dyslexia. This theme fell under semantic content which is explicit and more descriptive. This theme was a big influence on how each individual coped with dyslexia and how they all felt about having dyslexia. Most of the initial feelings towards dyslexia before being diagnosed were negative and adverse. All participants reported feelings of frustration and distress due to the lack of support and peers not understanding. Tanner ${ }^{38}$ reported similar findings, feelings of powerlessness and frustrations were described by adults with dyslexia due to the lack of understanding from teachers and peers. A lot of the frustration grew from having to work twice as hard as their peers, not being able to perform or keep up with other class mates, as well as being lost in the system by not being noticed or diagnosed at an earlier age. Morgan \& Klein ${ }^{17}$ found that adults with dyslexia feel cheated and frustrated for all things they missed because they were not assessed when they were still in school.

\section{Anger/frustration}

Many of the participants were frustrated with the teachers also, as themselves and the teachers knew the ability of the individual, however, the misunderstanding of their way of learning had them labelled as 'lazy' and 'a failure'. Such negative labels not only affected the way the participants felt, but also how they performed and developed intellectually and emotionally. Malcom described the frustration as feeling hard done by:

you feel hard done by sometimes, the frustration of not being able to read fluently like everyone else, instead it takes several days to understand, sometimes it gets to me but then overall I feel more determined'.

Disappointment alongside obvious distress is what several of the participants felt, especially when they were younger and undiagnosed. This was down to the expectations from others around them and also the way they were treated. Michael described the feeling of embarrassment and disappointment: 'growing up and moving to secondary school was confusing as well as embarrassing, I was behind on my literacy and I just could not understand why I wasn't like every other kid. Why could I not do things like my friends could? I felt more disappointed in myself every time I brought home a school report with nothing to show for my parents to be proud of'.

Negative comments or actions including bullying is what some of the participants had to experience, through enduring name calling most of their childhood as the other children simply did not understand, nor were they taught to think different from the teachers. Teachers need more training in recognising learning disabilities to put an end to bullying. Children need to have a better education in the different ways other children learn and why they behave differently or act differently to themselves. Michael expressed his feelings from name calling:

'...I would always get called stupid or dumb for mixing up my words or misunderstanding what is written on the board. It really made me upset and feel down all the time'.

\section{Stupid/lazy}

All participants expressed the feelings towards the negative labels they were given from teachers and peers. Stupid and lazy were the most common labels and had a detrimental effect of each of their selfesteem and emotional state. As just mentioned above, negative labels and name calling are a form of bullying. It is unacceptable that even teachers were involved with such a vulgar and frowned upon act when they are supposed to be the models dealing with it and putting an end to bullying. Alice describes the upset behind these labels:

'growing up was a negative experience with no support and many teachers calling me lazy and would say "stop being stupid and just try" like I wasn't trying hard enough'.

One of the hardest experiences that people with dyslexia have to endure is negatively from loved ones and friends. This can have a significant impact on their lives, their self-esteem and their image of themselves. This can have a more detrimental affect than 
the discrimination from teachers and peers. We expect more love and support from our family and friends as they are the ones who generally know us better and want the best for us, but sometimes people experience the same negatively as those who don't know us or don't care whether we achieve or not. Maisy described the feeling a family member who didn't understand dyslexia and her behaviour:

'I would get called lazy people thought I didn't want to read, they thought I just used it as an excuse to not go to school. When I was in year 6 my aunt told me about my homework, she said I was lazy and dumb, not knowing that I didn't understand it. It made me awkward and upset, like a failure'.

\section{Relief}

Despite the negative emotions throughout primary and secondary school life, once diagnosed, all participants began to see a positive change in their lives. Dyslexia was accepted by all for the positive aspects it offered them. Riddick $(2000)^{39}$ found for some people who have dyslexia, that the label had a positive effect on them. Dyslexia for the participants was perceived more as a gift rather than a disability as it made each individual more creative as their brains work differently compared to those who don't have dyslexia. They were able to visualise things in a way that non-dyslexic people cannot. Expressing the feeling of relief once being diagnosed was one of the biggest positives all participants shared. As Janice described, up until diagnosis, every day was a struggle:

'It was definitely a relief because you're going through school and education thinking what's wrong with me why can't I keep up... everything has actually improved, everyone is more supportive and they understand me better now'.

This feeling of weight being lifted off their shoulders made a huge impact in their lives in a positive way. To have a reason for their mistakes and to make sense of how they acted would result in higher self-esteem and a more positive look on life. Alice also described feelings of relief and happiness when she was diagnosed at the beginning of university:

II was always embarrassed and distressed through secondary school as I could not keep up with my friends...finding out what the root of the problem was, it was the biggest relief ever. Knowing what dyslexia was gave me the confidence I needed for a long time as I was able to accept myself and see the positive aspects to dyslexia like my creative side'.

Malcom believed the best thing about knowing he was dyslexic is that it changed everything for the better:

I'm always striving for better and trying hard to accomplish a target. When I finally reach that target there is no better feeling. It's like dominos, I succeed in something challenging and then I get the acceptance and praise I have always deserved from my peers. It feels wonderful. Then the circle starts again, I become more enthusiastic from my last challenge to start a new one'.

\section{Understanding learning styles}

The second theme that developed was the different learning styles that each participant had. Three learning styles were identified from the participants: visual, verbal and auditory. Learning styles are very important to people with dyslexia as their preferred style is partially the key to their academic success. Each learning style helps the individual to understand what they are learning and to make the most out of their learning. 'Learning style is the type of strategy used when an individual's cognitive style is applied to a learning situation' (Mortimore, 2003: 7). ${ }^{18}$ Through appropriate teaching methods and by using their preferred learning style, a person with dyslexia will be able to achieve their targets. Further research into learning styles has confirmed that performance in learning improves when an individual is taught according to their preferred style. (Mortimore, 2003; Reid, 2005). ${ }^{18,33}$ By understanding the way they learn and with appropriate tutorials and the right feedback, students with dyslexia can be guided by their individual learning style. From this, developmental learning strategies in a supportive environment can be created and applied for each individual.

\section{Visual (spatial)}

Visual (spatial) learning refers tothe use of vision. Learners prefer using images, colours and maps to help organise their information and communicate with others. Learners are able to visualise plans and outcomes, with using drawings and doodling as a form of note taking. Janice discussed an effective technique that she used for learning:

'I am quite a visual learner I can look at information ex amount of times in order to process it but also writing it down helps...I write up all my lecture notes using diagrams and attractive colours that catch my eye...I just keep rereading them, once I feel comfortable that I have the basis I can then build on it'.

Chasty $(1985)^{40}$ suggested that if a student cannot learn in the way the teacher teaches, then the teacher must teach in a way the student learns. This suggestion raises the awareness that some education institutions need to abide by this as many students are slipping through the system and failing due to misunderstanding of what they are being taught. To support the evidence further for the importance of preferred learning style with special reference to dyslexia, Exley $(2003)^{41}$ confirms that all the students who took part in the study improved their performance and attainment once their preferred learning style was recognised and they were taught accordingly.

There are many different learning styles and ways of learning, and indeed it is difficult for a teacher to adopt every single style into each lecture to suit the needs of each individual, however more attention should be paid to students who are in need of extra help. Large class sizes make it challenging to produce a lecture that is easily comprehended for all, but with the right preparation and willingness from the lecturers, students with dyslexia will be able to get the most out of learning by using their preferred learning styles and effective techniques.

\section{Auditory (listening)}

The auditory learning style refers to learning through listening. Recordings, music and sounds are all methods a learner will use to process information. The use of sound and rhyming in information helps a learner to focus on the content of information. Malcom mentioned that his learning style is auditory, as reading and writing are not his strengths, however he is a good listener:

'With learning, I like to listen. I'm a good listener. So I record my lectures and mentor sessions and make little easy simple notes for me to understand on the main points brought up. That's how I learn'. 


\section{Verbal (linguistic)}

The final learning style discovered from the participants was verbal (linguistic). This learning style involves the use of written and spoken word. Learners tend to use methods of rhyming, acting out and role play for the processing of information. Public speaking and debating are also ways to help learn new information. Techniques include using mnemonics, assertions, acronyms or singing the information to a familiar jingle. Michael described how his verbal learning helps him to process and manage his workload:

'I learn a lot verbally so I like speaking too. And I like listening to others speak then interpreting it in my own way so I understand... I'm also good at expressing myself through actions and role-play and with words and I apply this to learning, I use rhymes and acronyms and mnemonics to help with revision.

\section{Self-concept}

The final theme that derived from the data was self-concept, which was divided into strengths, weaknesses, self-image and selfbelief. This theme was more of the latent content category; this is more implicit and underlying because of the certain feelings gathered from the descriptions that participants shared of their experiences. By recognising their strengths and weaknesses, their opinions of their self-images and beliefs were later enhanced and they felt more determined to overcome their weaknesses. All participants ended up having a positive image and strong belief about themselves, with only a few minor weaknesses and more impactful and constructive strengths as an outcome.

\section{Self-esteem}

The self-esteem of each participant was tainted growing up due to failings in school, being the subject of bullying and no one to understand them as well not understanding themselves. Their overall evaluation of their emotional state and own worth was very low. This was noted especially around secondary school time when each of the participants had better understanding of emotions and feelings. Morgan \& Klein ${ }^{17}$ found that perceptions of self-esteem were likely to be lower among recently diagnosed adults. All participants suffered with lower self-esteem however some were more severe than others. This was the case for two out of five participants, however this may likely be due to the difference in age as both Janice and Maisy are a lot older than the rest of the participants meaning they are both mature students who spent some adult life undiagnosed. Maisy detailed that her self-esteem was affected mostly due to late diagnosis:

'When I started university I was 27. Imagine what it was like to go through most of your 20's bouncing through jobs and trying to get by thinking I was dumb. My jobs consisted mainly of retail and caring where little reading and writing was required. Only in my first year at uni which was my foundation year was I diagnosed. I was upset before this time by not knowing what was wrong with me, I would get cross with myself...I felt very low'.

\section{Self -belief}

Once being diagnosed, self-perception altered for all participants in an encouraging way. The identification answered their questions and put an end to self-blame. In turn, an understanding about themselves and determination to succeed grew as they wanted to prove others they can accomplish challenges like anyone else. Michael described his image and self-belief as life changing:

'Before I was diagnosed, I had no confidence and few friends. I didn't know how to interact as I felt stupid so I didn't integrate with some of the smarter kids. Then after I was diagnosed I finally understood who I was. I thought better of myself and was less bitter. Everyone noticed the transition and how much happier I was. It was life changing, I believed I could achieve anything I wanted to, and I believed I was different but unique. I was able to accept myself'.

Malcom also expressed the positivity in his life since being diagnosed as dyslexic:

'Things have changed drastically for the better. Like I said, things are more positive, I feel so much better about myself'.

Morgan and Klein (2000) ${ }^{17}$ believed that once a person is assessed in adulthood, they can have a significant impact on helping the next generation gain access to support and resources. Janice backed this belief up with her willingness and encouragement of helping other dyslexic students:

'...being a mentor and I now have three students with dyslexia, and I actually love it because I feel like I'm coming from a place where we share the same problems...I want to do some work with that ...to get other children to understand those with disabilities'.

A lot of the positive feelings were experienced also arose due the amount of support given. Before diagnosis, very little, if any help was being given to the participants which had a negative effect on their achievement's and self-esteem. With the right support and encouragement from teachers, participants were given an extra booster with their self-esteem. The problems each individual faced and the severity of them varied, however all had very similar outcomes when it came to being given the correct and appropriate support. Riddick ${ }^{5}$ spoke to mothers of children with dyslexia and found that the mothers who had teachers that understood their child better had formed a good relationship with their child helping improve their self-esteem and confidence. The mothers also emphasised the importance of encouragement and praise as being key qualities in relation to being a good teacher. By teaching students to overcome their weak points by compensating with their strengths, the person's belief in themselves heightens as well as their confidence and self-image. Alice referred to such encouragement as a highlight of university:

I devour most of my free time in trying to find way to make my weak points stronger and overcome them. I compensate my weakness in reading by balancing it with my strength in art and design. My lecturer helps me to understand and overcome my weaknesses by using my strengths as a way to understand the material, like a learning style. Without the support and encouragement of my mentor and lecturers, I would have dropped out of uni...the support is the highlight of uni for me'.

\section{Strengths/Weaknesses}

Participants were asked to share what they perceived to be strengths and weaknesses when it comes to learning. All participants shared similar weaknesses including reading, writing and memory; however they all had different strengths. Some participants described their strengths as coping strategies, creativity and skills. 
Specific Learning Difficulties such as dyslexia are linked to a range of skills, which some participants mentioned having. Each participant saw these skills as a strength. Some skills can include the likes of creativity, visual-spatial skills, understanding how things work, practical activities, lateral thinking abilities and originality. All people with dyslexia will have comparative strengths and will often demonstrate great determination, motivation and perseverance. From diagnosis, those with dyslexia were more open minded as they became to comprehend the disability allowing them to feel more comfortable and less conscious of others perceptions of them. Dyslexia was considered a gift through the chances that were given to do things that others would require more time and effort to do so. Alice found her creative side to be rewarding and as a strength, and without dyslexia, she didn't think her creative streak would have been revealed:

'I would not change how I am, with a choice I would choose to have dyslexia every time. I love that my brain thinks differently and uniquely, I am very creative. I can think in pictures to construct ideas in my head, so I can imagine things vividly before I actually do them. Without dyslexia and the way I use my brain differently, I wouldn't be able to do this'.

A common problem that all participants struggled with was their inability to express themselves in written form e.g. essay writing. Essays was the one thing that directly affected all participants. Miles \& Varma $^{42}$ revealed that the examination period for a dyslexic student was the most stressful time due to the pressures of working against time, careful and selective reading as well as writing excessively. It was very tiring and with students with dyslexia suffering from the lack of ability to express their thoughts on paper, many students described this as incredibly stressful. Michael expressed how much he struggles with the exam period:

I really struggle with my exams and assignments. Exams a lot more than assignments but still struggle with both.... I often feel like I'm going to fail and feel overwhelmed.... I hate exams. They are too hard. To sit there for 1-2 hours writing constantly is my worst night mare. I can't concentrate. I can't get any help I can't even take a break it's the worst experience ever'.

Note taking during lectures is another frequent problem, all participants faced difficulty with keeping up with the speed of the lecturer and making sense of what they were trying to write down. It is a complex skill for people with dyslexia as it places a heavy load on the working memory, which all participants expressed problems with their short term memory. This problem also produces issues due to the expectation of reading large amounts of text within a limited period. Ways of dealing with this involved the use of a dictaphone, pre-prepared lecture notes, and the use of a mentor/tutor. Having said this, all participants expressed strengths that they focus on more to outweigh the weaknesses. Some also mentioned trying to overcome their weaknesses by working on them to develop and turn those weaknesses into strengths. Michael shared how he has developed his weakness in his writing skills by using exercises to improve:

'Over the years I have managed to develop ways of coping though. My writing has definitely approved with constantly doing new exercises and I do enjoy it I feel proud and I have accomplished something big when I can write in bigger amounts with few mistakes'.

Despite sustaining negative experiences, all participants considered dyslexia as a positive aspect of their lives instead of a negative aspect as it gave them all the option to be more creative and more determined. All participants were happy to disclose their experiences as being dyslexic and when asked if they think they would prefer a life without dyslexia, the answer was no. Identifying strengths and overcoming weaknesses is what all people with dyslexia will have to face for the rest of their lives, throughout uni moving towards employment. Overcoming weak points and gaining new strengths help to improve self-esteem and confidence. Self-esteem plays an important role in the development of an individual. Teachers and lecturers as well as parents and friends should all encourage and praise that person to help them improve their confidence and recognise their abilities.

All participants were overall content with the support they received from their university, however all shared similar views on the late diagnosis. Frustration and the feeling of missed opportunity as well as feeling let down by the education system were all views shared by participants. Through continuity of positive emotions, determination and motivation and support, participants and other people who have dyslexia will be able to achieve their goals and be just as successful as people who do not have dyslexia. ${ }^{43-45}$

\section{Conclusion}

As mentioned previously, people with dyslexia are consistently misunderstood by their family, peers and educators because there is no obvious signs as it is a hidden disability. This makes it increasingly hard to recognise and diagnose. Due to the small number of professionals and people within the education system who can identify the signs and relate it to the disability, people with dyslexia in the meantime have to endure negative experiences from their loved ones and teachers who can see potential in that individual but fail to explain the academic failings. As a result, adults who are accessed later in life have lower self-esteem compared to those that were assessed as children. ${ }^{17}$ Throughout this proposal during the analysis process, such negative feelings and emotions were expressed by all participants as all of them were diagnosed at a late age and all endured the lack of support throughout primary and secondary school.

Voices of those coping with dyslexia is essential for future research, however, more research as mentioned before needs to be directed towards specifically the education system itself by targeting teachers, lecturers and those who control the examination process and regulations. Teachers and lecturers need to have raised awareness and appropriate training for managing dyslexia and other specific learning difficulties appropriately and effectively. Relationships should be established between the appropriate support teams and students with learning difficulties in order to create a cohesive process from each student. Coping strategies and preferred learning styles are indispensable to each individual student as these will help towards dictating their academic achievements. Communication channels between support services and supervisors with the student need to be accessible at all times without difficulty, this will help ensure the student to be positive and amicable throughout their journey of higher education.

Some charities and institutions are already applying the diversity amongst their students and are developing their own programmes. A programme from teacher awareness called The 'SPELLIT' programme researched into literacy learning run by the Dyslexia Institute (an educational charity). This programme found that teachers were aware of dyslexia and able to identify children with literacy difficulties. This 
is incredibly vital however, teachers involved in the programme often lacked the time and training necessary to follow up on the children who were identified as requiring extra support. Another weakness to this programme is that the Initial teacher training courses are very short and rarely involve more than basic awareness training. Even though specialist dyslexia training can be accessed through professional development courses, this extra course depends on the schools having sufficient resources. However, courses may vary significantly due to some courses being independently accredited, as there is no systematic scheme of accreditation. The British Dyslexia Association (BDA) says that "not all disability offices at universities are equally well trained and supportive".

From this lack of training and support or understanding of dyslexia, BDA specified that many intellectual and bright students often slip through education without being noticed for identification and diagnosis. From this, the BDA campaigns for training to be mandatory in teacher training courses.

Another association, the Dyslexia Research Trust (DRT) also stress the importance for correct and appropriate training as well as early identification to ensure a brighter future for students with dyslexia. Dr Anna Pitt, a researcher of DRT said, "It is likely that dyslexics who make it to university are adept at creating effective strategies for coping with less familiar tasks presented when entering higher education". The DRT are working towards identifying dyslexia in children before reading difficulties even manifest. Once identified, students in higher education with special needs should be able to receive the right kind of support to help them achieve as much as any other student. Teachers should encourage students with dyslexia to sit near to the front of the lecture in order to see and her clearly when it may not be possible to adapt the teaching style specifically for dyslexic students due the large number of students within the lecture theatre. Students should be encouraged to ask questions when something is unclear and to eliminate the reluctance to do so in front of a big audience as any questions raised can help the class as a whole.

Identifying each students with dyslexia learning style is incredibly significant as mentioned before. All of the participants involved with this proposal stressed the importance of learning style and how their particular learning style is adapted to their studying to be able to understand the material and develop their knowledge in each module. For this, tailored support should be provided to ensure each individual gets the most out learning and education. Students should be helped with developing effective metacognitive strategies and should consider alternative forms of assessment that are not focused on the traditional written exam in order to give every student the equal amount of chance for academic achievement.

Another incredibly valuable and significant point raised from one of the participants in this study and from previous research is the need for an up to date assessment for dyslexia. A lot of students and children need to be correctly diagnosed and the assessment needs to be carried out by trained and experienced professionals whether they may be a psychologist or a teacher. ${ }^{9}$ Understandably, the difficulties of dyslexic adults do not end when university and studies are over, so the importance for awareness in the communities and societies is essential so appropriate support continues into the workplace unless the individual is able to go forward and enter a career where their position is minimised in the need of reading and writing.
Future research will be useful to those with dyslexia as well as the families, friends, peers, teachers/lecturers and future employers around them. Dyslexia needs more research conducted on its origin to predict the likelihood of children being dyslexic in terms of genetics and brain differences. More research needs to be conducted into how support and guidance can be given, not just by institutions but from society as a whole. Coping strategies and learning styles as well as management need to be practiced and applied in the institutional settings with appropriate and professional training given. A must is to fund the research and training for early identification in children, and once diagnosed to follow guidelines in order to ensure that each child can receive the well needed support and advice to further them in their academic successes. Universities and colleges should be prepared to accommodate all the students and their needs, however good practice of such a nature should begin in school and continue throughout in higher education.

\section{Reflexive statement}

The chosen subject of dyslexia became of interest to me a few years ago when I first started learning about it in A-levels at sixth form. Throughout my years at university, I have developed a greater understanding towards dyslexia, however it was still unclear to me on how we can improve the lives of those who have dyslexia. I was especially interested in the emotional and psychological effects that dyslexia might have in people's lives: a hidden disability that could not be treated with drugs. I had several concerns initially when I pitched my idea to my supervisor; ethical considerations, sample size, and the general interest of the participants. Firstly ethical clearance was granted which put my mind at ease, however sample size remained a fear. There are many students within my chosen institution who have dyslexia, however only a small amount came forth to participate. This was frustrating yet saddening at the same time as the whole point of this study was to hopefully improve their quality of teaching and experience throughout university. It was recommended to gather at least six participants, however I only managed to interview five in total. Having said this, with my small sample, I was still able to gather a significant amount of detail in my data to help generate suggestions for future research. This led me to conclude that my sample size was appropriate for the amount of information provided, however a bigger sample and even sample (in terms of male to female ratio) would have still been more substantial, but this can be a suggestion for future research. There was also issues with the recruitment of participants as the online website used was not visited often. Recruitment mainly came through word of mouth and knowing participants who were eligible. This was not a predominant issue as I was still able to complete my study and gather detailed information. My experiences throughout the interviews with participants was insightful and extremely valuable to me. I gained the deepest insights of some of the participants who I thank for being so open and honest with me. I gained profound knowledge about dyslexia and was able to develop each new interview from the previous one by noting down and evaluating what went well and what could have went better. By practising this technique, the final interview felt completely relaxed, conversational and controlled without any issues or worries. Lastly, worries struck me with the difficulties in picking themes as there were so many identified in each interview. With all the rich and revealing details produced in each transcript, trying to characterise the infinite ways and feelings of each participants experiences' deemed harder as more information was revealed. Having said this, I am satisfied 
with the themes that arose as I believed they were complex yet easily comprehended enough for others to get the true picture.

Overall, the experience throughout the study from start to end has been incredibly valuable and exciting to see my own work progress before my eyes. I have a professional interest in dyslexia and I believe this proposal has given me great insight and understanding into the subject.

\section{Acknowledgements}

There are so many people who I wish to thank but I shall only mention a few; who are most important behind all of my achievements.

To my mother and father for always supporting me through every decision I made. To my brother, there is no other like you. You always remind me of the positives and always motivate me to do better. I thank my supervisor Siobhan Lynam throughout this whole journey, keeping me on track and motivating me so I can achieve a better outcome. To the rest of my family and friends for being supportive and helping me out as much as they can.

\section{Conflict of interest}

The author declares no conflict of interest.

\section{References}

1. Farmer M, Riddick B, Sterling C. Dyslexia and Inclusion. Assessment \& Support in Higher Education. London: Whurr; 2002.

2. Gisbon S, Kendell L. Support for Learning. 2010;25(4):187-193.

3. Michail K. Living with dyslexia. Unpublished Masters Dissertation. Theu University of Birmingham; 1998.

4. Braun V, Clarke V. Using thematic analysis in psychology. Qualitative Research in Psychology. 2006;3:77-101.

5. Riddick B. Living with Dyslexia. London: Routledge; 1996.

6. Miles TR. Dyslexia: The Pattern of Difficulties. London: Whurr Publishers; 1993.

7. Schneider E, Crombie M. Dyslexia and Foreign Language Learning London: David Fulton Publishers; 2003.

8. Smith C. Problems with reading, Support for Learning. 1993;8(4):139145.

9. Singleton CH, Cottrell SNG, Gilroy D, et al. Dyslexia in Higher Education: Policy, Provisions and Practice. Hull: University of Hull; 1996.

10. BDA. Dyslexia Research Information. 2009.

11. Dyslexic label being applied too widely, expert argues. 2014.

12. Miles E. Can there be a single definition of dyslexia? Dyslexia. 1995;1(1):37-45.

13. International Dyslexia Association (IDA). What Is Dyslexia? 2002.

14. Grigorenko EL. Developmental dyslexia: An update on genes, brains, and environments. Journal of Child Psychology and Psychiatry. 2001;42(1):91-125.

15. Hurford DM. To read or not to read: Answers to all your questions about dyslexia. New York: A Lisa Drew Book/Scribner; 1998.

16. Edwards J. The Scars of Dyslexia. London: Cassell; 1994.
17. Morgan E, Klein C. The dyslexic Adult in a non-dyslexic world. London: Whurr; 2000.

18. Mortimore T. Dyslexia and Learning Style: A Practitioner's Handbook. London: Whurr; 2003.

19. Watkins D, Dong Q. Assessing the self-esteem of Chinese school children Educational Psychology. 1994;14(1):129-137.

20. Scott R. A counsellor's perspective on dyslexia. In: Thomson M, editor Dyslexia included: A whole school approach. London: David Fulton; 2003.

21. Dale M, Taylor B. How adult learners make sense of their dyslexia. Disability \& Society. 2001;16(7):997-1008.

22. Long L, Macblain S, Macblain M. Bridging theholistic and academic divide: beyond the mechanics of learning to read. Journal of Adolescent \& Adult Literacy. 2007;51(2):124-134.

23. Hall W. Dyslexia in the Primary Classroom. Exeter: Learning Matters Ltd; 2009.

24. Fawcett AJ, Nicolson RI. The dyslexia early screening test. Irish Journal of Psychology. 1995;16(3):248-259.

25. Donawa W. Growing up Dyslexic: A Parent's View. Journal of Learning Disabilities. 1995;28(6):324-328.

26. Cain C. Dyslexics at Brown. A Student Perspective. RI: Brown University; 1987.

27. Chanock, K. Working together: how universities support dyslexic students in their studies. In: Bryer F, editor, Making meaning: creating connections that value diversity: 30th Annual Conference of the Australian Association of Special Education 23-25 September 2005. Australia: Australian Association of Special Education; 2005. p. 171-178.

28. Mortimore T. Dyslexia and Learning Style - A Note of Caution. British Journal of Special Education. 2005;32(3):145-148.

29. Riddick B, Farmer M, Sterling C. Students and Dyslexia. Growing with a Specific Learning Difficulty. London: Whurr; 1997.

30. Cameron $\mathrm{H}$, Nunkoosing K. Lecturer perspectives on dyslexia and dyslexic students within one faculty at one university in England. Teaching in Higher Education. 2012;17(3):341-352.

31. Ritchie J, Lewis J. Qualitative Research Practice. A guide for social science students and researchers. London: Sage Publishers; 2003.

32. Al-Busaidi ZQ. Qualitative Research and its Uses in Health Care. Sultan Qaboos University Medical Journal. 2008;8(1):11-19.

33. Reid D. Learning styles and Inclusion. London: Sage; 2005.

34. Briggs CL. Learning how to ask: a sociolinguistic appraisal of the role of the interview in social science research. Cambridge: Cambridge University Press; 1986.

35. Boyatzis, R. E. Transforming Qualitative Information. Thematic analysis and code development. Cleveland: Sage publications; 1998.

36. Kvale S. Interview: An Introduction to Qualitative Research Interviewing. Sage Publications; 1996.

37. Christians CG. Ethics and politics in qualitative research. In: Denzin NK, Lincoln YS, editors. The landscape of qualitative research: Theories and Issues. 2nd ed. Thousand Oaks: Sage; 2003.

38. Tanner K. Adult dyslexia and the "conundrum of failure". Disability \& Society. 2009;24(6):785-797. 
39. Riddick B. An examination of the Relationship Between labelling and stigmatisation with Special reference to Dyslexia. Disability \& Society. 2000;15(4):653-667.

40. Chasty H. what is dyslexia? In: Snowling MJ, editor. Children's Written Language Difficulties. Windsor: NFER Nelson; 1985.

41. Exley S. The effectiveness of teaching strategies for students with dyslexia based on their preferred learning styles. British Journal of Special Education. 2003;30(4):213-220.
42. Miles TR, Varma V, editors. Dyslexia and Stress. London: Whurr; 1995.

43. Carden P. The LAMS design for diversity, leadership, followership and case study of dyslexic children. Developmental Science. 2007;9:237-255.

44. Dyslexia and Specific Learning Difficulties in Adults. (n.d.). 2015.

45. My Child Is Struggling With Studies. What Should I Do? (n.d.). 2015. 